\title{
The complete chloroplast genome sequence of Brachypodium
} distachyon: sequence comparison and phylogenetic analysis of eight grass plastomes

\author{
Esteban Bortiri, Devin Coleman-Derr, Gerard R Lazo, Olin D Anderson and \\ Yong Q Gu*
}

\begin{abstract}
Address: Genomics and Gene Discovery Research Unit, USDA-Agriculture Research Service, Western Regional Research Center, 800 Buchanan Street, Albany, CA 94710, USA

Email: Esteban Bortiri - ebortiri@gmail.com; Devin Coleman-Derr - colemanderr@yahoo.com; Gerard R Lazo - Gerard.Lazo@ars.usda.gov; Olin D Anderson - olin.anderson@ars.usda.gov; Yong Q Gu* - yong.gu@ars.usda.gov

* Corresponding author
\end{abstract}

Published: 31 July 2008

BMC Research Notes 2008, I:6I doi:10.1 186/1756-0500-I-6I
Received: 5 May 2008

Accepted: 31 July 2008

This article is available from: http://www.biomedcentral.com/1756-0500/I/6I

(C) 2008 Bortiri et al; licensee BioMed Central Ltd.

This is an Open Access article distributed under the terms of the Creative Commons Attribution License (http://creativecommons.org/licenses/by/2.0), which permits unrestricted use, distribution, and reproduction in any medium, provided the original work is properly cited.

\begin{abstract}
Background: Wheat, barley, and rye, of tribe Triticeae in the Poaceae, are among the most important crops worldwide but they present many challenges to genomics-aided crop improvement. Brachypodium distachyon, a close relative of those cereals has recently emerged as a model for grass functional genomics. Sequencing of the nuclear and organelle genomes of Brachypodium is one of the first steps towards making this species available as a tool for researchers interested in cereals biology.
\end{abstract}

Findings: The chloroplast genome of Brachypodium distachyon was sequenced by a combinational approach using BAC end and shotgun sequences derived from a selected $B A C$ containing the entire chloroplast genome. Comparative analysis indicated that the chloroplast genome is conserved in gene number and organization with respect to those of other cereals. However, several Brachypodium genes evolve at a faster rate than those in other grasses. Sequence analysis reveals that rice and wheat have a $\sim 2.1 \mathrm{~kb}$ deletion in their plastid genomes and this deletion must have occurred independently in both species.

Conclusion: We demonstrate that BAC libraries can be used to sequence plastid, and likely other organellar, genomes. As expected, the Brachypodium chloroplast genome is very similar to those of other sequenced grasses. The phylogenetic analyses and the pattern of insertions and deletions in the chloroplast genome confirmed that Brachypodium is a close relative of the tribe Triticeae. Nevertheless, we show that some large indels can arise multiple times and may confound phylogenetic reconstruction.

\section{Findings}

Plastids are key organelles of green plants, carrying out functions like photosynthesis, starch storage, nitrogen and sulfate metabolism, and synthesis of chlorophyll, car- otenoids, fatty acids and nucleic acids [1]. Plastids have multiple copies of a circular, double-stranded DNA chromosome, each with a set of approximately 110 genes highly conserved in sequence and organization [2]. 
In addition to their important biological roles, plastids have the potential to make a big impact on biotechnology. Plastid transformation, achieved via homologous recombination, is very advantageous compared to nuclear genome transformation mainly because it can generate high levels of gene expression and the recombinant DNA is more easily contained since chloroplasts are maternally inherited in most species of angiosperms [3].

The family Poaceae, with approximately 10,000 species, contains the world's most important crops. The tribe Triticeae, of subfamily Pooideae, includes species grown in temperate regions, some of which are of great economic importance; i.e., wheat, rye, triticale, and barley. Despite their contribution to human food supply, members of the Triticeae are not easily amenable to functional genomics aimed at crop improvement because of their large genome size and difficulty in transformation.

Brachypodium distachyon, a small grass in the Pooideae, has recently emerged as a new model species for functional genomics of temperate grasses. Brachypodium offers many advantages as a model grass; among them, its reduced stature, short life cycle, and small genome [4].

In the last few years a considerable effort has been made to develop genetic and molecular tools for Brachypodium, including ESTs [5], Bacterial Artificial Chromosome (BAC) libraries [6], cytological characterization of accessions [7-9], and techniques to perform rapid and efficient transformation $[10,11]$. Finally, sequencing of the Brachypodium distachyon genotype $\mathrm{Bd} 21$ has been initiated by the DOE Joint Genomics Institute and will soon be available to the public.

Here we report the sequencing of the chloroplast genome of the Bd21 genotype of Brachypodium, and perform a sequence analysis and phylogeny reconstruction with the completely sequenced chloroplast genomes from seven grass species. We compare the evolutionary dynamics of Brachypodium chloroplast genes with those of wheat, rice and maize, and discuss the significance of some indels in the framework of grass evolution.

\section{Sequencing of the Brachypodium chloroplast genome}

Sequencing of plastid genomes is usually done by isolation of chloroplasts followed by purification and amplification of plastid DNA for library construction. To sequence the chloroplast genome of Brachypodium distachyon, we took advantage of existing BAC libraries [12] and identified several chloroplast BACs from a database of BAC end sequences (BES). In our analysis, 1,725 BES matched wheat chloroplast queries. Clones generated from a single restriction of the chloroplast genome should contain the entire chloroplast genome and its two BES would assemble in the same region in opposite orientations. The two BES from BAC DH037I03 matched backto-back the sequence of the wheat $p s b C$ gene (Fig. 1C). Overall, we identified over 30 BACs harboring the complete chloroplast genome, suggesting that this strategy is efficient in identifying full-length chloroplast genomes from genomic BAC libraries.

As expected, the chloroplast sequence assembled using the BES contained many gaps due to the distance between restriction sites (Fig. 1). To complete the Brachypodium chloroplast genome, a shotgun sequencing library of DH037I03 was constructed. The complete genome sequence was assembled using 1,725 $\mathrm{BES}, 410$ sequences from the shotgun library, and 264 gap-filling sequences generated by primer walking. The sequence coverage of the entire chloroplast genome is $8.9 \times$.

\section{Genome organization of Brachypodium chloroplast}

The chloroplast genome of Brachypodium distachyon is 135,197 bp in length. The Inverted Repeats (IR) are 21,540 bp in length each, and the Large Single Copy (LSC) and Small Single Copy (SSC) regions are 79,446 bp and 12,668 bp long respectively. The Brachypodium chloroplast genome contains 118 unique genes, 18 of which are duplicated in the IRs, making a total of 136 genes of known function. In addition, there are 9 predicted open reading frames (ORFs) and 3 tRNA pseudogenes. With a few exceptions discussed below, the gene number and order are identical to other grass chloroplast genomes (Fig. 2).

\section{Grass chloroplast phylogeny based on complete chloroplast genomes}

In a landmark article that included data from multiple sources, the Grass Phylogeny Working Group [13] examined relationships among grasses using a large and diverse assemblage of species. That study highlighted the existence of two major lineages, the BEP clade and the PACCAD clade, that together encompass the majority of grasses. The BEP clade includes the subfamilies Bambusoideae, Ehrhartoideae, and Pooideae. Rice belongs to subfamily Ehrhartoideae while wheat, barley, bentgrass, and Brachypodium are in the Pooideae. The PACCAD clade includes several subfamilies, among them the Panicoideae, a large group of mainly tropical and subtropical species, some of which are important crops worldwide, like maize, sugarcane, and sorghum.

So far, all phylogeny reconstructions of the Poaceae have used selected genes or partial regions as data. However, with sequenced chloroplast genomes of several species in this family and the computer power to align them, it is possible for the first time to perform whole chloroplast genome phylogenic analyses. To examine if the genome- 
A

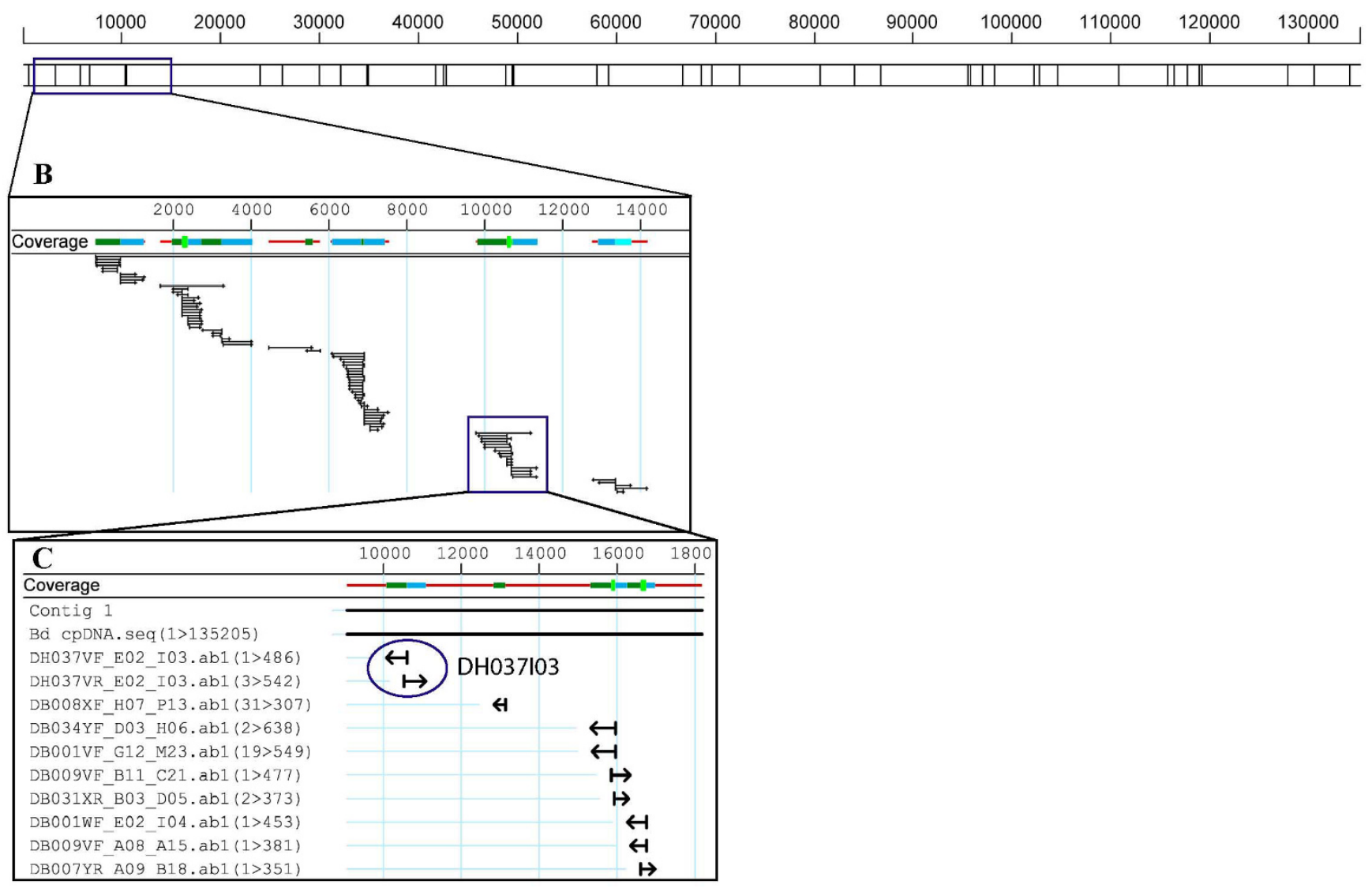

Figure I

BAC end sequences (BES) coverage of the Brachypodium distachyon plastid chromosome. A: There are 43 Hindlll sites in the Brachypodium and wheat plastid genomes, which explain the distribution of BAC end coverage. B: The Brachypodium BAC end sequences (BES) were assembled using the wheat chloroplast genome as a scaffold. C: clone DH037103 contains the entire Brachypodium chloroplast genome indicated by its back-to-back BES (circled).

wide phylogenic analysis is consistent with those based on selected genes, we employed Bayesian [14] and Maximum Parsimony [15] methods to reconstruct a grass phylogeny using whole chloroplast sequences. Both Bayesian and Maximum Parsimony estimates produced the same topology with maximum node support (Fig. 3). The topology shown on Fig. 3 contained 99\% of the Bayesian credible trees and the tree is in agreement with the results obtained with a larger group of species [13]. The phylogram also shows that branches in the BEP clade are much longer than those in the PACCAD clade. A similar result was found by Saski et al. [16] in a phylogenetic study using 61 protein-coding genes, indicating that the rates of evolution are higher in the BEP clade compared to the PACCAD species sampled here. However, it is possible that these slower rates do not extend to other species of the PACCAD clade, since maize, sorghum, and sugarcane are closely related, with all three belonging to subfamily Panicoideae.

\section{Evolution of Brachypodium chloroplast genes}

For a given protein-coding gene, the proportion of substitutions that do not cause a change in the amino acid sequence (synonymous) to those that do (nonsynonymous) is a commonly used estimator of the evolutionary dynamics operating on that gene [15]. To find out if Brachypodium plastid genes show the same evolutionary dynamics as other grasses we calculated the ratio of nonsynonymous to synonymous substitution rates for Brachypodium chloroplast genes using tobacco as an outgroup.

We found that the nonsynonymous/synonymous ratios for Brachypodium chloroplast genes are similar to those of rice, maize and wheat, with photosynthetic genes having 

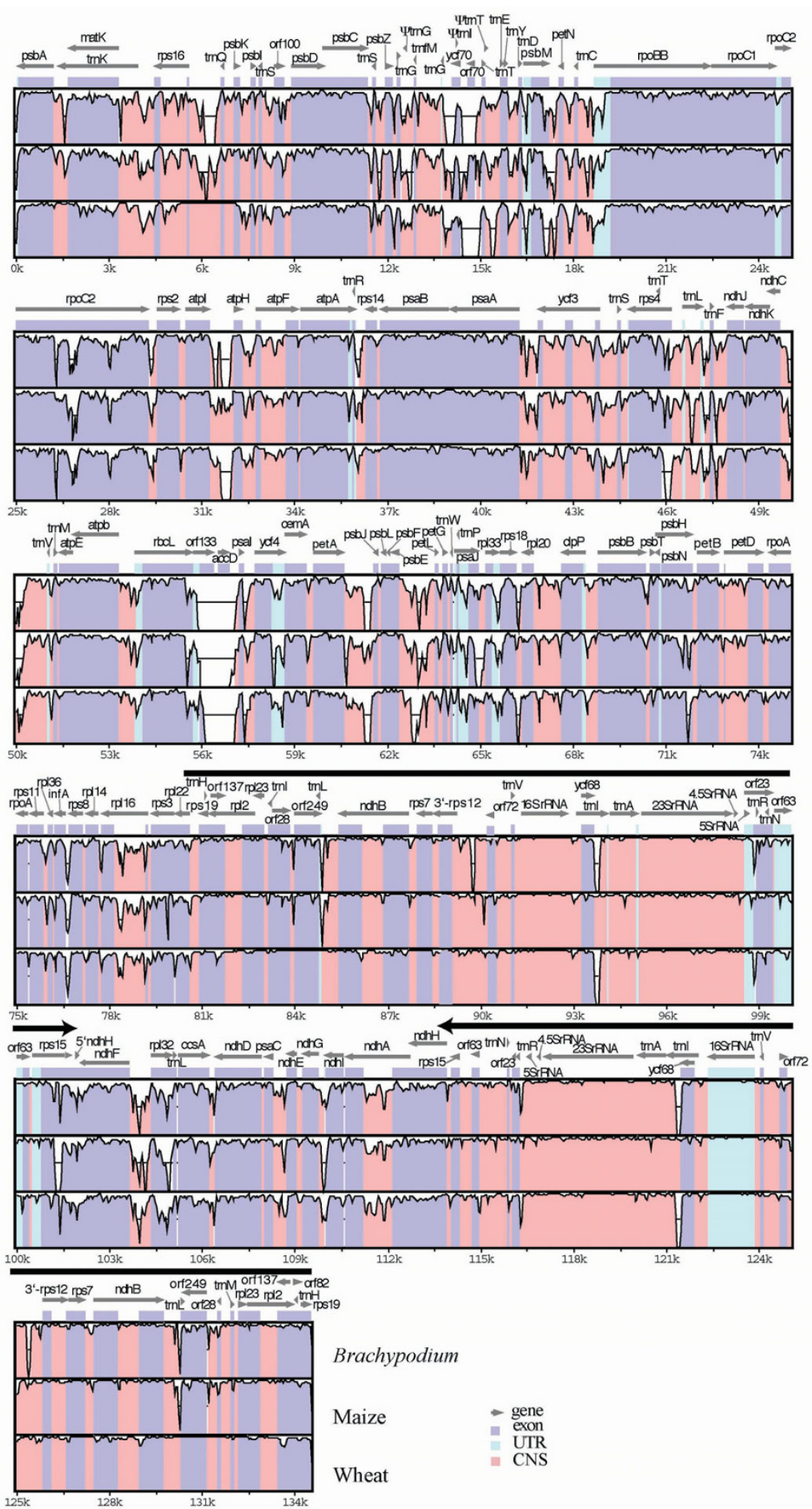

Figure 2

Alignment of grass chloroplast genomes. The sequence of rice chloroplast genome is compared to those of Brachypodium (top alignment), maize (middle), and wheat (bottom). Sequences were aligned in mVISTA [24] and the annotation shown above the alignment corresponds to the rice genome. Grey arrows above the alignment indicate genes and their orientation. Colors indicate location of exons, conserved non-coding sequences (CNS), and untranslated regions (UTRs). Ribosomal genes are colored as CNS. Thick black lines show the position of the IRs. Other grass genomes mentioned in the text have been omitted for the sake of simplicity. 


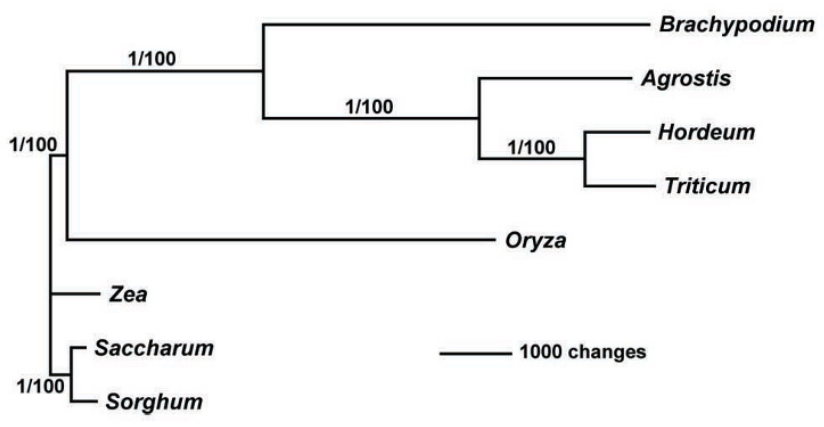

Figure 3

Complete chloroplast genome phylogeny of the grasses. The phylogram was obtained from an exhaustive parsimony search and was the same to a topology obtained from a Bayesian analysis. The tree was rooted making maize, sugarcane, and sorghum the outgroup. Support for the nodes is shown as posterior probability after 1000000 generations and bootstrap values from 1000 repetitions. The GenBank accesions used for the analyses are XI590I (rice), EU325680 (Brachypodium), EFI I5543 (bentgrass), EFI I554I (barley), X86563 (maize), AP0067I4 (sugarcane), EFII5542 (sorghum), and $\mathrm{AB} 042240$ (wheat). The sequences were aligned and visualized using mVISTA [25]. MrBayes [14] and PAUP* [24] were used to analyze the data.

the lowest ratio (Table 1), in agreement with previous findings [17]. Within the NADH class, $n d h \mathrm{~B}$ and $r p s 12$ have very low rates of both kinds of substitutions compared to other genes in the same class, a result explained by their position, in the IRs and most likely due to the dynamics of the IRs' evolution rather than to evolutionary constrains on $n d h \mathrm{~B}$ and $\operatorname{rps} 12$.

The rate of evolution of a particular gene; i.e., the estimated number of substitutions per site, can vary among different organisms for reasons like rapid gene duplication that creates opportunity for sequence divergence, different generation time, and various DNA repair mechanisms [15]. We conducted a relative rate test [18] for all Brachypodium chloroplast genes with known function against their orthologs in maize, wheat, and rice and found that most Brachypodium genes evolve at similar rates to those of wheat, rice, and maize. However, there are unequal rates of evolution (at $P=0.05$ ) in 15 genes and 17 cases of species comparisons, and Brachypodium genes evolved at a faster rate in 14 out of those 17 comparisons (Table 2).

\section{Sequence comparison among grass chloroplast genomes}

The structure and gene number of the chloroplast genome is very similar among land plants, although the Poaceae have three large inversions compared to the canonical plastid genome usually represented by the tobacco chloroplast genome [19]. This conservation of overall struc- ture in the chloroplast genomes of grasses allowed us to align the chloroplast genome sequences of eight grass species at the genome-wide level.

Comparison of the sequences of eight chloroplast genomes (only rice, Brachypodium, wheat, and maize are represented on Fig. 2) reveals several regions of high sequence length polymorphism, as well as shared deletions and insertions. The IRs show lower sequence divergence among grasses than the single-copy region (Fig. 1), a result previously reported by other authors [20]. The region between $r b c \mathrm{~L}$ and $p s a \mathrm{I}$ (at position $\sim 54 \mathrm{~kb}$, Fig. 2 ) is one of the most polymorphic chloroplast loci in grasses. In rice, this region is 1532 bp long and contains ORF133 and the accD gene, but it is much shorter in other grasses. In Brachypodium, both ORF133 and accD are missing, and the entire $r b c \mathrm{~L}-p s a \mathrm{I}$ spacer region, containing only the $r b c \mathrm{~L}$ 3'UTR and psaI promoter sequences, is reduced to $296 \mathrm{bp}$ long.

As expected from its phylogenetic placement, Brachypodium shares several indels with barley, wheat, and bentgrass, all of which are in subfamily Pooideae, including a 410 bp deletion in ORF70 ( $14.5 \mathrm{~kb}$, Fig. 2$)$ and the duplication of a 5 ' portion of $n d h \mathrm{H}$ IRb ( $102 \mathrm{~K}$ in Fig. 2$)$ that is also shared with rice $[16,21]$. The size of this duplication is variable, ranging from $238 \mathrm{bp}$ in rice to $311 \mathrm{bp}$ in Brachypodium. Insertions in rpoC2 ( 25 K, Fig. 2) have been described and used previously in phylogenetic analyses [[13], and references therein] and will not be discussed here.

\section{Rice and wheat have identical and independently derived deletions}

Despite the overall sequence conservation of IRs, the region between $n d h \mathrm{~B}$ and $t r n \mathrm{I}(\sim 84 \mathrm{~K}$ and $\sim 131$ in Fig. 2) appears to be a hot spot for large indels. Previously, Ogihara et al [21] described a 2,131 bp deletion in wheat and rice with respect to maize. This deletion is located between ORF249 and ORF28 ( $~ 84 \mathrm{~K}$ and $131 \mathrm{~K}$, Fig. 2). Because rice is more closely related to wheat than to maize, the authors concluded that the deletion was present in the common ancestor of rice and wheat. However, this deletion is present only in rice and wheat, which are not sister species (Fig. 3), whereas in Brachypodium, barley, and bentgrass there is a smaller deletion of about 1,141 bp (Fig. 4).

To confirm that the 2,131-bp deletion in rice and wheat was not an artifact of the alignment or missing sequence, we used the Brachypodium sequence missing in wheat and rice and blasted it against grass sequence databases. We recovered sequences from many grasses except wheat and rice, confirming the presence of the deletion in their genomes. In addition, we searched the GenBank 
Table I: Substitution rates in grasses. Chloroplast genes are divided into seven groups according to the function of their product. For groups of more than one gene the top row gives the mean substitution rate, and the second and third rows show the genes, within that group, with the maximum and minimum rates respectively. ENV: Envelope membrane. MAT: maturaseK. NADH: NADH genes. PS: Photosynthetic genes. RP: ribosomal genes. RNPol: RNA polymerase genes. B: Brachypodium. W: wheat. R: rice. M: maize.

\begin{tabular}{|c|c|c|c|c|c|c|c|c|c|c|c|c|c|}
\hline \multirow[t]{2}{*}{$\begin{array}{l}\text { GENE } \\
\text { GROUP }\end{array}$} & \multirow[t]{2}{*}{$\begin{array}{l}\text { No. OF } \\
\text { GENES }\end{array}$} & \multicolumn{4}{|c|}{ SYNONYMOUS SUBSTITUTIONS' } & \multicolumn{4}{|c|}{ NONSYNONYMOUS SUBSTITUTIONS' } & \multicolumn{4}{|c|}{$\begin{array}{c}\text { NNONSYNONYMOUS/SYNONYMOUS } \\
\text { RATIO }\end{array}$} \\
\hline & & B & w & $\mathbf{R}$ & $\mathbf{M}$ & B & w & $\mathbf{R}$ & $\mathbf{M}$ & B & w & $\mathbf{R}$ & $\mathbf{M}$ \\
\hline RNPol & 4 & 0.371 & 0.359 & 0.358 & 0.36 & 0.131 & 0.126 & 0.131 & 0.128 & 0.35 & 0.35 & 0.37 & 0.35 \\
\hline $\operatorname{Max}$ & & $\begin{array}{r}r p o C l \\
0.452\end{array}$ & $\begin{array}{r}\text { rpoCl } \\
0.423\end{array}$ & $\begin{aligned} \text { rpoCl } \\
0.428\end{aligned}$ & $\begin{array}{c}\text { rpoCl } \\
0.42\end{array}$ & $\begin{array}{r}\text { rpoc2 } \\
0.172\end{array}$ & $\begin{array}{r}\text { rpoc2 } \\
0.162\end{array}$ & $\begin{array}{c}\text { rpoC2 } \\
0.166\end{array}$ & $\begin{array}{l}r p o C 2 \\
0.159\end{array}$ & $\begin{array}{c}r p o C 2 \\
0.6\end{array}$ & $\begin{array}{c}\text { rpoC2 } \\
0.57\end{array}$ & $\begin{array}{c}\text { rpoC2 } \\
0.61\end{array}$ & $\begin{array}{c}\text { rpoc2 } \\
0.54\end{array}$ \\
\hline Min & & $\begin{array}{l}r p o C 2 \\
0.289\end{array}$ & $\begin{array}{r}\text { rpoC2 } \\
0.286\end{array}$ & $\begin{array}{l}\text { rpoC2 } \\
0.273\end{array}$ & $\begin{array}{c}\text { rpoC2 } \\
0.296\end{array}$ & $\begin{array}{l}\text { rpoB } \\
0.088\end{array}$ & $\begin{array}{l}r p o B \\
0.084\end{array}$ & $\begin{array}{l}\text { rpoB } \\
0.087\end{array}$ & $\begin{array}{l}r p o B \\
0.089\end{array}$ & $\begin{array}{c}\text { rpoCl } \\
0.24\end{array}$ & $\begin{array}{l}\text { rpoB } \\
0.24\end{array}$ & $\begin{array}{c}\text { rpoCl } \\
0.25\end{array}$ & $\begin{array}{c}\text { rpoCl } \\
0.25\end{array}$ \\
\hline ENV & I & 0.46 & 0.454 & 0.422 & 0.44 & 0.2 & 0.193 & 0.2 & 0.188 & 0.44 & 0.43 & 0.47 & 0.43 \\
\hline MAT & 1 & 0.448 & 0.47 & 0.466 & 0.45 & 0.225 & 0.209 & 0.212 & 0.213 & 0.5 & 0.44 & 0.46 & 0.47 \\
\hline NADH & 11 & 0.362 & 0.354 & 0.358 & 0.36 & 0.092 & 0.092 & 0.091 & 0.09 & 0.25 & 0.26 & 0.25 & 0.25 \\
\hline Max & & $\begin{array}{l}n d h \mathrm{H} \\
0.463\end{array}$ & $\begin{array}{l}n d h \mathrm{H} \\
0.46 \mathrm{I}\end{array}$ & $\begin{array}{l}n d h \mathrm{H} \\
0.445\end{array}$ & $\begin{array}{l}n d H A \\
0.448\end{array}$ & $\begin{array}{l}n d h F \\
0.188\end{array}$ & $\begin{array}{l}n d h F \\
0.18\end{array}$ & $\begin{array}{l}n d h F \\
0.18 I\end{array}$ & $\begin{array}{l}n d h F \\
0.172\end{array}$ & $\begin{array}{l}n d h F \\
0.55\end{array}$ & $\begin{array}{l}n d h F \\
0.53\end{array}$ & $\begin{array}{l}n d h F \\
0.5 I\end{array}$ & $\begin{array}{l}n d h F \\
0.49\end{array}$ \\
\hline Min & & $\begin{array}{l}n d h B \\
0.062\end{array}$ & $\begin{array}{l}n d h B \\
0.076\end{array}$ & $\begin{array}{l}\text { ndhB } \\
0.059\end{array}$ & $\begin{array}{l}n d h B \\
0.065\end{array}$ & $\begin{array}{l}n d h B \\
0.028\end{array}$ & $\begin{array}{l}n d h B \\
0.04\end{array}$ & $\begin{array}{l}\text { ndhB } \\
0.029\end{array}$ & $\begin{array}{l}\text { ndhB } \\
0.025\end{array}$ & $\begin{array}{l}\text { ndhC } \\
0.125\end{array}$ & $\begin{array}{c}n d h \mathrm{H} \\
0.14\end{array}$ & $\begin{array}{c}n d h \mathrm{H} \\
0.13\end{array}$ & $\begin{array}{c}n d h \mathrm{H} \\
0.15\end{array}$ \\
\hline PS & 32 & 0.370 & 0.362 & 0.353 & 0.36 & 0.039 & 0.041 & 0.039 & 0.039 & 0.11 & 0.12 & 0.11 & 0.11 \\
\hline Max & & $\begin{array}{l}p s a C \\
0.554\end{array}$ & $\begin{array}{l}\text { psaC } \\
0.571\end{array}$ & $\begin{array}{l}\text { psaC } \\
0.519\end{array}$ & $\begin{array}{l}\text { psaC } \\
0.485\end{array}$ & $\begin{array}{c}a t p E \\
0.158\end{array}$ & $\begin{array}{c}a t p E \\
0.158\end{array}$ & $\begin{array}{l}a t p \mathrm{E} \\
0.15\end{array}$ & $\begin{array}{c}a t p E \\
0.147\end{array}$ & $\begin{array}{l}a t p \mathrm{E} \\
0.42\end{array}$ & $\begin{array}{l}a t p F \\
0.42\end{array}$ & $\begin{array}{l}a t p F \\
0.47\end{array}$ & $\begin{array}{l}a t p F \\
0.53\end{array}$ \\
\hline Min & & psbL 0.2 & $\begin{array}{l}p s b L \\
0.16\end{array}$ & $\begin{array}{l}p s b L \\
0.16\end{array}$ & $\begin{array}{l}p s b L \\
0.16\end{array}$ & $\begin{array}{l}\text { petG, } \\
\text { psbl } 0\end{array}$ & $\begin{array}{l}\text { petG, } \\
\text { psbl } 0\end{array}$ & $\begin{array}{c}\text { petG } \\
\text { psbM } \\
\text { psbT } 0\end{array}$ & $\begin{array}{c}\text { petG, } \\
\text { psbF } \\
\text { psbl } \\
\text { psbT } 0\end{array}$ & $\begin{array}{l}\text { petD } \\
1.24 \times \\
10^{-2}\end{array}$ & $\begin{array}{c}\text { petB } \\
9.52 \times \\
10^{-3}\end{array}$ & $\begin{array}{c}\text { petD } \\
1.7 \times \\
10^{-2}\end{array}$ & $\begin{array}{c}\text { petD } \\
6.83 \times \\
10^{-3}\end{array}$ \\
\hline PR & 1 & 0.442 & 0.412 & 0.426 & 0.427 & 0.161 & 0.161 & 0.168 & 0.161 & 0.36 & 0.39 & 0.39 & 0.38 \\
\hline $\mathbf{R P}$ & 22 & 0.312 & 0.297 & 0.302 & 0.287 & 0.121 & 0.121 & 0.127 & 0.121 & 0.39 & 0.41 & 0.42 & 0.42 \\
\hline Max & & $\begin{array}{c}r p s 8 \\
0.489\end{array}$ & $\begin{array}{l}r p s 8 \\
0.469\end{array}$ & $\begin{array}{l}r p s 8 \\
0.48\end{array}$ & $\begin{array}{l}r p s 8 \\
0.47\end{array}$ & $\begin{array}{l}r p / 22 \\
0.251\end{array}$ & $\begin{array}{l}r p / 22 \\
0.248\end{array}$ & $\begin{array}{l}r p / 22 \\
0.256\end{array}$ & $\begin{array}{l}r p / 22 \\
0.256\end{array}$ & $r p / 2$ I.I & $\begin{array}{l}r p / 2 \\
0.98\end{array}$ & $\begin{array}{l}r p / 2 \\
1.18\end{array}$ & $\begin{array}{l}r p / 2 \\
1.18\end{array}$ \\
\hline Min & & $\begin{array}{l}r p s 12 \\
0.05\end{array}$ & $\begin{array}{l}r p s 12 \\
0.045\end{array}$ & $\begin{array}{l}r p s \mid 2 \\
0.05\end{array}$ & $\begin{array}{l}r p s 12 \\
0.056\end{array}$ & $\begin{array}{l}r p s 12 \\
0.028\end{array}$ & $\begin{array}{l}r p s 12 \\
0.028\end{array}$ & $\begin{array}{l}r p s 12 \\
0.035\end{array}$ & $\begin{array}{l}r p s 12 \\
0.026\end{array}$ & $\begin{array}{c}\text { rps } 14 \\
0.2\end{array}$ & $\begin{array}{l}\text { rpll6 } \\
0.21\end{array}$ & $\begin{array}{c}r p s \mid 4 \\
0.2\end{array}$ & $\begin{array}{c}r p s 14 \\
0.18\end{array}$ \\
\hline
\end{tabular}

I Rates were calculated using the method of Nei and Gojobori [27] using tobacco as an outgroup to Brachypodium, wheat, rice, and maize.

angiosperm databases with the maize sequence corresponding to the deleted wheat and rice region and found that the region is present in species representing diverse lineages of flowering plants, including the monocot Dioscorea, the early-diverging angiosperms Amborella and Nymphaea, and several core eudicots (data not shown). Therefore, we concluded that the 2,131-bp deletions in the wheat and rice chloroplast genomes are derived characters that arose independently in those species.

The 2,131-bp deletions in rice and wheat are identical in both IRs and the sequences bordering them align unambiguously with those of other grasses (Fig. 4). In addition, the lack of direct short repeats in sequences indicates that
Maize

Bentgrass

Brachypodium

Barley

Rice

Wheat

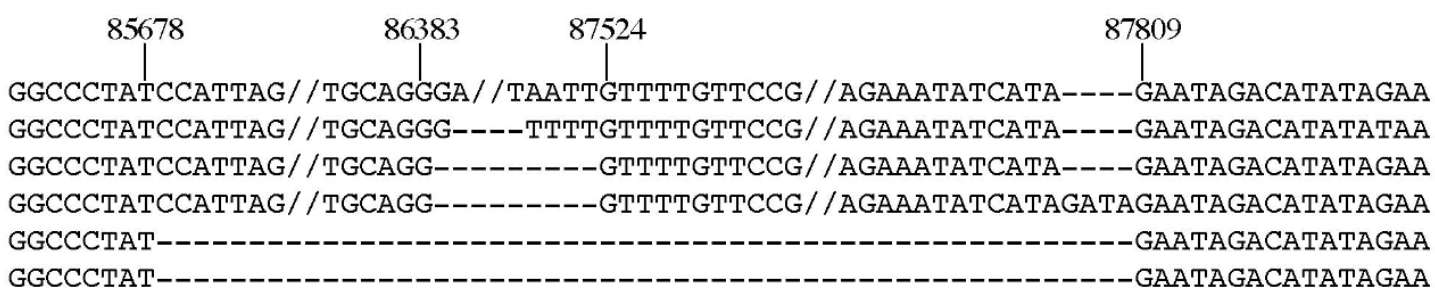

\section{Figure 4}

Deletions in the IR region. Rice and wheat have an identical $2.1 \mathrm{~kb}$ deletion in both IRs (indicated by the dashes). Brachypodium, bentgrass, and barley have a $1.14 \mathrm{~kb}$ deletion in the same region. The sequences flanking the deletions are shown. The positions shown on top of the alignment correspond to the maize sequence. Two slashes indicate that the sequence continues but is not shown here. 
Table 2: Summarized results of Tajima's [18] test of relative evolution of Brachypodium chloroplast genes compared with those of wheat, rice, and maize. The $P$ value of genes that evolve at significantly different rates in Brachypodium is shown for each gene and species comparison. When $P<0.05$, indicating that rates are significantly different, the species with the highest rate of evolution is shown in parenthesis. B: Brachypodium, W: wheat, R: rice, M: maize.

\begin{tabular}{|c|c|c|c|}
\hline \multirow[t]{2}{*}{ Gene } & \multicolumn{3}{|c|}{ Species pair comparison } \\
\hline & B vs W & B vs $R$ & B vs. M \\
\hline petA & $0.04(W)$ & 1 & 0.87 \\
\hline petB & 0.23 & 0.79 & $0.04(B)$ \\
\hline psbB & 0.67 & $0.04(B)$ & 0.17 \\
\hline psbH & 0.37 & $0.02(\mathrm{~B})$ & 1 \\
\hline rpsII & $0.011(B)$ & 0.089 & 0.23 \\
\hline rps 14 & 0.48 & 0.11 & $0.03(B)$ \\
\hline rps4 & 0.47 & $0.039(B)$ & 0.22 \\
\hline$r p / 2$ & $0.00042(\mathrm{~W})$ & 0.44 & $0.033(\mathrm{~B})$ \\
\hline$r p / 20$ & $0.011(B)$ & 0.64 & 0.18 \\
\hline$n d h B$ & $0.00023(\mathrm{~W})$ & 0.66 & 0.47 \\
\hline$n d h l$ & 0.18 & $0.003(B)$ & $0.02(\mathrm{~B})$ \\
\hline trnl & $0.046(B)$ & 0.059 & I \\
\hline rpoCl & $0.017(\mathrm{~B})$ & 0.13 & 0.088 \\
\hline rpoC2 & $0.008 \mathrm{I}(\mathrm{B})$ & 0.055 & 0.062 \\
\hline ycfo & $0.025(\mathrm{~B})$ & 0.71 & 0.76 \\
\hline
\end{tabular}

recombination via short repeats is not the way by which they arose. Thus, despite the fact that deletions of varying lengths in the ndhB-trnI region seem to be common in the BEP clade, the mechanism underlying these specific deletions remains unclear. In tobacco, nucleotide mutations in plastid coding sequences are quickly eliminated by gene conversion, a process facilitated by the polyploid nature of the plastid genome [22]. Whatever the mechanism is that generates deletions in the $\operatorname{trn} \mathrm{I}-n d h \mathrm{~B}$ region in species of the BEP clade, their multiple occurrences suggests that they may provide a selective advantage to those species in order to overcome gene conversion and become fixed in the population.

\section{Competing interests}

The authors declare that they have no competing interests.

\section{Authors' contributions}

EB did the sequence alignment and comparison, the phylogenetic analyses, the relative tests of evolution, and drafted the manuscript. DC-D performed the BAC end sequence searches, BAC shotgun library construction and sequencing, sequence assemblage, and substitution rates analyses. GRL wrote the algorithm to search BES with wheat queries and assembled BES on the genome. YGU designed and coordinated the study. Both OA and YQG supervised the work and collaborated in the manuscript preparation. All authors have read and approved the final version of the manuscript.

\section{Acknowledgements}

We thank Naxin Huo for her help with BAC end sequencing. This work was supported in parts by the United State Department of Agriculture, Agriculture Research Service CRIS projects 532502100-010 and 532502100-011.

\section{References}

I. Staehelin LA, Newcomb EH: Membrane structures and membranous organelles. In Biochemistry and Molecular Biology of Plants Edited by: Buchanan BB, Gruissem W, Jones RL. Rockville, MD: American Society of Plant Biologists; 2000:37-45.

2. Palmer JD: Plastid chromosomes: structure and evolution. In The molecular biology of plastids Cell culture and somatic cell genetics of plants Volume 7A. Edited by: Hermann RG. Vienna: Springer; 1991:5-53.

3. Bock R: Plastid biotechnology: prospects for herbicide and insect resistance, metabolic engineering and molecular farming. Current Opinion in Biotechnology 2007, 18:100-106.

4. Garvin DF, Gu YQ, Hasterok R, Hazen SP, Jenkins G, Mockler TC Mur LAJ, Vogel J: Development of genetic and genomic research resources for Brachypodium distachyon, a new model system for grass crop research. The Plant Genome [A Supplement to Crop Science] 2008, I:S-69-84.

5. Vogel J, Gu YQ, Twigg P, Lazo G, Laudencia-Chingcuanco D, Hayden DM, Donze TJ, Vivian LA, Stamova B, Coleman-Derr D: EST sequencing and phylogenetic analysis of the model grass Brachypodium distachyon. Theoretical and Applied Genetics 2006, I I3(2): I86-195.

6. Huo N, Gu YQ, Lazo G, Vogel J, Coleman-Derr D, Luo M-C, Thilmony R, Garvin DF, Anderson OD: Construction and characterization of two BAC libraries from Brachypodium distachyon, a new model for grass genomics. Genome 2006, 49: 1099-I 108.

7. Hasterok R, Draper J, Jenkins G: Laying the cytotaxonomic foundations of a new model grass, Brachypodium distachyon (L.) Beauv. Chromosome Research 2004, I 2:397-403.

8. Jenkins G, Hasterok R: BAC 'landing' on chromosomes of Brachypodium distachyon for comparative genome alignment. Nature Protocols 2007, 2:88-98.

9. Hasterok R, Marasek A, Donnison IS, Armstead I, Thomas A, King IP, Wolny E, Idziak D, Draper J, Jenkins G: Alignment of the genomes of Brachypodium distachyon and temperate cereals and grasses using bacterial artificial chromosome landing with fluorescence in situ hybridization. Genetics 2006, 173:349-362.

10. Vogel J, Garvin DF, Leong O, Hayden DM: Agrobacterium-mediated transformation and inbred line development in the model grass Brachypodium distachyon. Plant Cell, Tissue and Organ Culture 2005, 84:199-2II.

II. Christiansen P, Andersen CH, Didion T, Folling M, Nielsen KK: A rapid and efficient transformation protocol for the grass Brachypodium distachyon. Plant Cell Reports 2005, 23:75I-758.

12. Huo N, Lazo G, Vogel J, You FM, Ma Y, Hayden DM, Coleman-Derr D, Hill TA, Dvorak J, Anderson OD, et al:: The nuclear genome of Brachypodium distachyon: analysis of BAC end sequences. Functional and Integrative Genomics 2007. electronic version.

13. GPWG: Phylogeny and subfamilial classification of the grasses (Poaceae). Annals of the Missouri Botanical Garden 200I, 88(3):373-457.

14. Huelsenbeck JP, Ronquist F: MRBAYES: Bayesian inference of phylogeny. Bioinformatics 200I, I7:754-755.

15. Nei M, Kumar S: Molecular Evolution and Phylogenetics. Oxford: Oxford Universiy Press; 2000.

16. Saski C, Lee S-B, Fjellheim S, Guda C, Jansen R, Luo H, Tomkins J, Rognli OA, Daniell H, Clarke JL: Complete chloroplast genome sequences of Hordeum vulgare, Sorghum bicolor, and Agrostis stolonifera, and comparative analyses with other grass genomes. Theoretical and Applied Genetics 2007, II 2(8): $1503-1518$.

17. Matsuoka $\mathrm{Y}$, Yamazaki $\mathrm{Y}$, Ogihara $\mathrm{Y}$, Tsunewaki K: Whole chloroplast genome comparison of rice, maize, and wheat: implications for chloroplast gene diversification and phylogeny of cereals. Molecular Biology and Evolution 2002, I 9(I 2):2084-2091.

18. Tajima F: Simple methods for testing the evolutionary clock hypothesis. Genetics 1993, 135:599-607. 
19. Doyle J], Davis JI, Soreng RJ, Garvin DF, Anderson MJ: Chloroplast DNA inversions and the origin of the grass family (Poaceae). Proceedings of the National Academy of Sciences 1992, 89:7722-7726.

20. Yamane K, Yano K, Kawahara T: Pattern and rate of indel evolution inferred from whole chloroplast intergenic regions in sugarcane, maize, and rice. DNA Research 2006, 13:197-204.

21. Ogihara $Y$, Isono K, Kojima T, Endo A, Hanaoka M, Shiina T, Terachi T, Utsugi S, Murata M, Mori N, et al.: Structural features of a wheat plastome as revealed by complete sequencing of chloroplast DNA. Molecular Genetics and Genomics 2002, 266:740-746.

22. Khakhlova O, Bock R: Elimination of deleterious mutations in plastid genomes by gene conversion. The Plant Journal 2006, 46:85-94.

23. Mayor C, Brudno M, Schwartz JR, Poliakov A, Rubin EM, Frazer KA, Pachter LS, Dubchak I: VISTA: Visualizing global DNA sequence alignments of arbitrary length. Bioinformatics 2000, 16:1046.

24. Swofford DL: PAUP*. Phylogenetic analysis using parsimony (*and other methods), version 4. Sunderland, Massachusetts, USA: Sinauer; 2003.

25. Nei M, Gojobori T: Simple methods for estimating the numbers of synonymous and nonsynonymous nucleotide substitutions. Molecular Biology and Evolution 1986, 3(5):418-426.

Publish with Biomed Central and every scientist can read your work free of charge

"BioMed Central will be the most significant development for disseminating the results of biomedical research in our lifetime. "

Sir Paul Nurse, Cancer Research UK

Your research papers will be:

- available free of charge to the entire biomedical community

- peer reviewed and published immediately upon acceptance

- cited in PubMed and archived on PubMed Central

- yours - you keep the copyright 